\title{
Ohmic Processing: Temperature Dependent Electrical Conductivities of Lemon Juice
}

\author{
Hosain Darvishi (Corresponding author) \\ Department of Mechanical Engineering, Islamic Azad University, Islamshar Branch,Tehran, Iran \\ Tel: 98-21-4419-4911-4 Fax: 9-21-4419-6524Ｅ-mail: Hosaindarvishi@yahoo.com
}

Adel Hosainpour

Department of Farm Machinery Mechanical Engineering, Ilam University, Ilam, Iran

E-mail: A_hosainpour12@yahoo.com

Farzad Nargesi

Department of Farm Machinery Mechanical Engineering, Ilam University, Ilam, Iran

E-mail: Farzad_Nargesi61@yahoo.com

Mohammad Hadi Khoshtaghaza

Department of Farm Machinery Mechanical Engineering, Tarbiat Modares University, Tehran, Iran

E-mail: Khoshtag@gmail.com

Hosain Torang

Department of Mechanical Engineering, Islamic Azad University, Islamshar Branch, Tehran, Iran

E-mail: H_Torang@yahoo.com

\begin{abstract}
Development of new technologies for thermal food treatment is still of great industrial and scientific interest. Ohmic heating is one of these new technologies. In this study, lemon juice was heated on a laboratory scale static ohmic at different voltage gradients in the range of $30-55 \mathrm{~V} / \mathrm{cm}$. The voltage gradient was statistically significant on the ohmic heating rates for lemon juice $(\mathrm{P}<0.05)$. Measurements were made from 20 to $74^{\circ} \mathrm{C}$ and showed a linear increase in electrical conductivity values with increasing temperature. The ohmic heating system performance coefficients were in the range of 0.54-0.92.
\end{abstract}

Keywords: Ohmic heating, Electrical conductivity, Lemon juice, Temperature, Performance coefficient

\section{Introduction}

Ohmic heating is a thermal process in which heat is internally generated by the passage of alternating electrical current (AC) through a body such as a food system that serves as an electrical resistance (Shirsat et al., 2004). The main advantages of ohmic processing are the rapid and relatively uniform heating achieved (Zareifard et al., 2003), ease of process control, High energy efficiency (Ghnimi et al., 2008), lower degradation of vitamin (Vikram et al., 2005), together with the lower capital cost compared to other electro heating methods such as microwave and radio frequency heating (Marra et al., 2009; Kim et al., 1998). Ohmic heating is considered very suitable for thermal processing of particulates in liquid foods because the particulates heated simultaneously at similar or faster rates than the liquid.

The amount of heat generated is directly related to the current induced by the voltage gradient in the field, and the electrical conductivity (Shirsat et al., 2004). Electro-technologies for food processing are cleaner, more environmentally friendly and energy efficient than conventional methods currently in use. In addition, electrical resistance heating can intensify both heat and mass transfer (Kemp and Fryer, 2007). Ohmic heating has been shown to enhance drying rates (Wang and sastry, 2000; Zhong and Lima, 2003) and extraction yields (Wang and Sastry, 2002) in certain fruits and vegetables. 
Icier and Ilicali (2005a) reported that the electrical conductivity increased linearly with increasing temperatures for fruit juices orange at voltage gradients ranging from 20 to $60 \mathrm{~V} / \mathrm{cm}$. Palanippan and Sastry (1991) reported that the electrical conductivity of the orange, carrot and tomato juices increased with temperature and decreased with solids content. Icier et al (2008) similarly found that the electrical conductivity increased as the temperature increased ranging from 0.4 to $0.75 \mathrm{~S} / \mathrm{m}$ for fresh grap juice. Amiali et al. (2006) studied that the electrical conductivity $(0.13$ to $0.63 \mathrm{~S} / \mathrm{m})$ increased linearly with increasing temperatures for fruit juices (namely apple, orange, and pineapple juices). The ohmic heating of fruit juice was studied at different voltage gradients ( 7.5 to $26.25 \mathrm{~V} / \mathrm{cm}$ ) by Kong et al. (2008). Results indicated that the voltage gradient significantly influenced the ohmic heating rates. Also, they found that the electrical conductivity changed significantly with temperature.

The aim of this study was to obtain electrical conductivity data for lemon juice during ohmic heating over the sterilization temperatures range. Effects of temperature and voltage gradients on ohmic heating rates of lemon juice were studied. Ohmic heating of lemon juice as a single phase were also mathematically modeled by taking the system performance coefficients into account.

\section{Materials and methods}

\section{1 samples}

The fresh lemon fruits used in this study were purchased from a local market in Tehran, Iran and stored at refrigeration conditions $\left(4^{\circ} \mathrm{C}\right)$ prior to experiments (not more than $6 \mathrm{hr}$ ). Fruits were washed with water to remove dirt on the skin; and then the water on the skin surface was drained. For experiment, the fruits were crushed and squeezed. The juice was filtered.

\subsection{Ohmic heating system}

A schematic diagram of the electrical circuitry is shown in Fig. 1. The experimental device consisted of a power supply, an isolating transformer, a variable transformer, microcomputer and three digital multimeters. The cell employed was constructed from Pyrex. The distance between two electrodes was $0.05 \mathrm{~m}$ and the diameter of the electrodes was $0.04 \mathrm{~m}$, resulting in a total sample volume of $53.8 \mathrm{ml}$. A K type thermocouple was inserted into the geometric center of the cell. The temperature at the center of the sample was used as the representative value, and was assumed to be spatially uniform because of its small size. The sample was sandwiched between two electrodes in the test cell. End caps, fitted with high grade stainless steel electrodes were held in place using a spring-loaded system which also served to prevent leakages. Temperature, current and voltage applied were monitored with three digital multimeter (ET-2230/2231, Minipa, China) and passed this information to the microcomputer with an RS 232 port at 1secend intervals. This allowed real-time calculation of the total power input to the sample at any given time (Kulshrestha and Sastry, 2006; Shirsat et al., 2004). The ohmic samples were heated at $30,35,45$ and $55 \mathrm{~V} / \mathrm{cm}$ at $60 \mathrm{~Hz}$ from $20^{\circ} \mathrm{C}$ to final temperature of $70^{\circ} \mathrm{C}$.

\subsection{Electrical conductivity}

Electrical conductivity $(\mathrm{S} / \mathrm{m})$ was calculated from voltage and current data using the following equation (Icier et al., 2008):

$$
\sigma=\mathrm{LI} / \mathrm{VA}
$$

where $\sigma$ is electrical conductivity $(\mathrm{S} / \mathrm{m})$; I is the current intensity (A), V is the voltage $(\mathrm{V}), \mathrm{L}$ is the gap between the electrodes $(\mathrm{m})$ and A is the electrode surface area $\left(\mathrm{m}^{2}\right)$.

\subsection{Mathematical model}

The energy given to the system during ohmic processing in unsteady state heat will be equal to the energy required to heat the sample plus the energy loss (Icier and Ilicali, 2005a,b):

$$
\begin{gathered}
\mathrm{E}_{\text {given }}=\mathrm{E}_{\text {taken }}+\mathrm{E}_{\text {loss }} \\
\sum(\mathrm{VIt})=\mathrm{m} \mathrm{C}_{\mathrm{p}}\left(\mathrm{T}_{\mathrm{f}}-\mathrm{T}_{\mathrm{i}}\right)+\mathrm{E}_{\text {Loss }}
\end{gathered}
$$

where $\mathrm{C}_{\mathrm{p}}$ is specific heat capacity $(\mathrm{J} / \mathrm{kg} . \mathrm{K}) ; \mathrm{m}$ is mass of the sample $(\mathrm{kg}) ; \mathrm{T}_{\mathrm{f}}$ is final temperature of the sample $\left({ }^{\circ} \mathrm{C}\right)$; $\mathrm{Ti}$ is initial temperature of the sample $\left({ }^{\circ} \mathrm{C}\right)$; $\mathrm{t}$ is time (s) Egiven is the electrical energy given to the system (J); and Eloss is the energy loss $(\mathrm{J})$

The energy loss term $\left(\mathrm{E}_{\text {loss }}\right)$ is the sum of the heat required to heat up the test cell, the heat loss to the surroundings by natural convection and the electrical energy which has not been converted into heat.

Since low $\mathrm{E}_{\text {loss }}$ would indicate, a system with a high performance, a system performance coefficient, SPC, was defined as; 


$$
\mathrm{SPC}=\mathrm{mC}_{\mathrm{p}}\left(\mathrm{T}_{\mathrm{f}}-\mathrm{T}_{\mathrm{i}}\right) / \sum(\mathrm{VIt})
$$

The voltage distribution within the sample for the quasi-static can be computed using the following Laplace low:

$$
\nabla(\sigma \Delta \mathrm{V})=0
$$

The average voltage gradient assuming that the voltage only changes in the axial direction can be written as:

$$
\nabla \mathrm{V}=\Delta \mathrm{V} / \mathrm{L}
$$

To simplify the calculation of balance during heating, the following assumptions were made:

(i) Specific heat capacity of the lemon juice is constant within the range of temperatures considered.

(ii) SPC is constant.

The energy balance becomes:

$$
\operatorname{SPC}\left(\Delta \mathrm{V}^{2} \sigma \mathrm{A} / \mathrm{L}\right)=\mathrm{m} \mathrm{Cp} \partial \mathrm{T} / \partial \mathrm{t}
$$

Eq. (6) was solved by the forward finite difference method numerically. The time step used in the computations was $0.01 \mathrm{~s}$. The physical properties used in the computations and the experimental parameters are given in Table 1. A nonlinear analysis of covariance was used to evaluate treatment combination differences. The experiments were replicated three times.

\section{Results and discussion}

\subsection{Effect of temperature and voltage gradient}

Results of the nonlinear analysis of covariance are shown in Table 2. The results indicated that that voltage gradient and temperature significantly altered (increased) the electrical conductivity value of lemon juice $(\mathrm{P}<$ $0.05)$.

The changes in electrical conductivity of lemon juice with temperature during ohmic heating at four different voltage gradients are given in Fig. 2. As shown in Fig. 2, the electrical conductivity increased as the temperature increased during ohmic heating. The results are similar to those reported by Kemp and Fryer (2007); Icier et al. (2008); Icier and Ilicali (2004 and 2005a, b); Li et al (2004); Zareifard et al (2003) and Tulsiyan et al (2008). Kemp and Fryer (2007); Icier et al. (2008) reported that the increase in the electrical conductivity values with temperature has been explained by reduced drag for the movement. The highest electrical conductivity was observed on $55 \mathrm{~V} / \mathrm{cm}$, followed by 45,35 and $30 \mathrm{~V} / \mathrm{cm}$. The electrical conductivity at $35 \mathrm{~V} / \mathrm{cm}$ was slightly higher than that at $30 \mathrm{~V} / \mathrm{cm}$. Similar observations were reported for grape juice (Icier et al., 2008), apple and sour cherry juice (Icier and Ilicali, 2004). Between 55 and $75^{\circ} \mathrm{C}$, the electrical conductivity at $40 \mathrm{~V} / \mathrm{cm}$ was slightly higher than that at 20 or $30 \mathrm{~V} / \mathrm{cm}$.

Cristina et al. (1999) reported that the electrical conductivity was dependent on the concentration ( ${ }^{\circ}$ Brix) and the temperature $\left(20-80^{\circ} \mathrm{C}\right)$ for lemon juice. The electrical conductivity increases with increasing concentration up to approximately $30^{\circ}$ Brix, when it starts to decrease. The decrease in electrical conductivity may be due to the increase in viscosity of the juices with concentration which decreases the mobility of the ions.

Since the experimental electrical conductivity results for the lemon juice samples given in Fig. 2 showed a linear trend with increasing temperature, a linear equation shown in Eq. (8) was used to fit the experimental data. The constants and the linear regression coefficients are given in Table 3.

$$
\sigma=\mathrm{B} \mathrm{T}+\mathrm{C}
$$

where $\mathrm{B}$ and $\mathrm{C}$ are constant; and $\mathrm{T}$ is temperature $\left({ }^{\circ} \mathrm{C}\right)$. High coefficients of determination $\left(\mathrm{R}^{2}>0.97\right)$ indicate the suitability of the linear model for conductivity variation with temperature.

At high voltage gradients, the current passing through the sample was higher and this increased the heat generation rate. As the voltage gradient increased the heating time of the lemon juice required to reach the prescribed temperature decreased. Other researchers who have found a linear increase in electrical conductivity with increase in temperature include Sarang et al (2008), Tulsiyan et al (2008), Legrand et al. (2007), Icier and Ilicali (2005a,b), Castro et al (2004), Li et al (2004), Zareifard et al (2003) and Fiala et al (2001). The experimental ohmic heating times required to raise the temperatures of the lemon juice from 20 to $74^{\circ} \mathrm{C}$ are given in Tables 4. The time required to heat the lemon juice from 20 to $74^{\circ} \mathrm{C}$ at $30 \mathrm{~V} / \mathrm{cm}$ was $1.64,2.18$ and 4 times longer than at 35, 45 and $55 \mathrm{~V} / \mathrm{cm}$, respectively. In addition to this, Icier and Ilicali (2004) reported that the decrease in the concentration of the apple and sour-cherry juices from $60 \%$ to $20 \%$ enhanced the ohmic heating rate of the juices. Icier and Ilicali (2005b) reported similarly that electrical conductivity depended on the drained the viscosity of the heated solution during ohmic heating. 


\subsection{Performance coefficient}

The mathematical model predicted smaller heating rate, which led to higher heating time than the experimental results. The electrical energies given to the system, the heat taken by the fruit juice concentrates, performance coefficients (SPC) and heating times for mathematical model calculated for each voltage gradient experiments are shown in Table 4 . For the $30 \mathrm{~V} / \mathrm{cm}$ voltage gradient SPC was approximately 0.92 , which indicated that $8 \%$ of the electrical energy given to the system was not used to heat up the test liquid. However, for higher voltage gradients, SPC values were lower and the heat required to heat up the test cell was too small to account for the energy loss term, Eloss. A similar observation was reported by Icier and Ilicali $(2004,2005 \mathrm{a})$ for orange juice, peach puree and apricot puree.

A portion of the electrical energy input was used for physical, chemical and electrochemical changes in the concentrate. It is rather difficult to comment on the exact nature of this loss. In industrial scale production it was concluded that not all of the electrical energy was converted into heat in the lemon juice concentrate. Because a steady state will be obtained as soon the system is heated, so it will be of lesser importance. The stainless steel electrodes caused electrochemical reactions in the food sample that not beneficial (Assiry et al., 2003). They suggested that the titanium coated electrodes using ohmically heating processing, because it could decrease these reactions. Thus, the kind electrodes had different effects during ohmic heating and the amount of energy used for electrochemical reactions.

From the experimental data obtained it is clear that this loss depends on the voltage gradient applied. For low voltage gradients, the conversion of electrical energy into heat was larger. Therefore, the system was performing better. The level of agreement between the predicted and experimental heating times was relatively good when these electrical conductivity models were used.

\section{Conclusion}

The electrical conductivity increased linearly with increasing of temperature. The electrical conductivity of lemon juice is strongly dependent on temperature. The rate of change of temperature for $55 \mathrm{~V} / \mathrm{cm}$ was higher than each other voltage gradients applied. Ohmic heating times and performance coefficients are dependent on the voltage gradient used. As the voltage gradient increased, time and performance coefficient decreased. This modeling procedure can be used for designing and controlling ohmic heating processes to ensure thermal sterilization and safety of ohmically heated food products.

\section{References}

Amiali, M., Ngadi, M., Raghavan, V. G. S., Nguyen, D. H. (2006). Electrical conductivities of liquid egg product and fruit juices exposed to high pulsed electric fields. International Journal of Food Properties, 9, 533-540.

Assiry, A., Sastry, S. K., Samaranayake, C. (2003). Degradation kinetics of ascorbic acid during ohmic heating with stainless steel electrodes Journal of Applied Electrochemistry, 33(2), 187-196.

Castro, A., Teixeira, J. A., Salengke, S., Sastry, S. K., Vicente, A. A. (2004). Ohmic heating of strawberry products: electrical conductivity measurements and ascorbic acid degradation kinetics. Innovative Food Science and Emerging Technologies, 5, 27-36.

Cristina, S. C., Moura, D.R., Vitali, A. D. A. (1999) .A Study of Water Activity and Electrical Conductivity in Fruit Juices: Influence of Temperature and Concentration. Brazil Journal Food Technology, 2, 31-38.

Fiala, A., Wouters, P, C., Bosch, E, D., Creyghton, Y. L. M. (2001). Coupled electrical-fluid model of pulsed electric field treatment in a model food system. Innovative Food Science \& Emerging Technologies, 2, 229-238

Ghnimi, S., Flach-Malaspina, N., Dresh. M., evaluation of an ohmic heating unit for thermal processing of highly viscous liquids. Chemical Engineering Research and Design, 86, 627-632.

Icier, F., Ilicali, C. (2004). Electrical conductivity of apple and sourcherry juice concentrates during ohmic heating. Journal of Food Process Engineering, 27(3), 159-180.

Icier, F., Ilicali, C. (2005a). The effects of concentration on electrical conductivity of orange juice concentrates during ohmic heating. European Food Research and Technology, 220(3), 406-414.

Icier, F., Ilicali, C. (2005b). Temperature dependent electrical conductivities of fruit purees during ohmic heating. Food Research International, 38, 1135-1142.

Icier, F., Yildiz, H., Baysal, T. (2008). Polyphenoloxidase deactivation kinetics during ohmic heating of grape juice. Journal of Food Engineering, 85, 410-417. 
Kemp, M. R., Fryer, P. J. (2007). Enhancement of diffusion through foods using alternating electric fields. Innovative Food Science and Emerging Technologies, 8, 143-153.

Kim, H. J., Choi, Y. M., Yang, A. P. P., Yang, T. C. S., Taub, I. A., Giles, J., Ditusa, C., Chall, S., Zoltai, P. (1996). Microbiological and chemical investigation of ohmic heating of particulate foods using a $5 \mathrm{~kW}$ ohmic system, Journal of Food Processing and Preservation, 20(1), 41-58.

Kong, Y. Q., Li, D., Wang, L. J., Bhandari, B., Chen, D. X., Mao, Z. H. (2008). Ohmic heating behavior of certain selected liquid food materials. International journal of food engineering, 4(3), 1-13.

Kulshrestha, A. S., Sastry, K. S. (2007). Low-frequency dielectric changes in cellular food material from ohmic heating: Effect of end point temperature. Innovative Food Science and Emerging Technologies, 7, 257-262.

Legrand, A., Leuliet, J. C., Duquesne, S., Kesteloot, R., Winterton, P., Fillaudeau, L. (2007). Physical, mechanical, thermal and electrical properties of cooked red bean (Phaseolus vulgaris L.) for continuous ohmic heating process. Journal of Food Engineering, 81, 447-458.

Li, F. D., Li, L. T., Li, Z., Tatsumi, E. (2004). Determination of starch gelatinization temperature by ohmic heating. Journal of Food Engineering, 62, 113-120.

Marra, F., Zell, M., Lyng, J. G., Morgan, D. J., Cronin, D. A. (2009). Analysis of heat transfer during ohmic processing of a solid food, Journal of Food Engineering, 91, 56-63.

Palaniappan, S., Sastry, S. K. (1991). Electrical conductivity of selected juices: influences of temperature, solids content, applied voltage, and particle size. Journal of Food Process Engineering, 14, 247-260.

Sarang, S., Sastry, S. K., Knipe, L. (2008). Electrical conductivity of fruits and meats during ohmic heating. Journal of Food Engineering, 87, 351-356.

Shirsat, N., Lyng, J. G., Brunton, N. P., McKenna, B. (2004). Ohmic processing: Electrical conductivities of pork cuts. Meat Science, 67, 507-514.

Tulsiyan, P., Sarang, S., Sastry. S. K. (2008). Electrical conductivity of multi component systems during ohmic heating. International Journal of Food Properties, 11, 233-241.

Vikram, V. B., Ramesh, M. N., Prapulla, S. G. (2005). Thermal degradation kinetics of nutrients in orange juice heated by electromagnetic and conventional methods. Journal of Food Engineering, 69, 31-40.

Wang, W. C., Sastry, S. K. (2000). Effects of thermal and electro thermal pretreatments on hot air drying rate of vegetable tissue. Journal of Food Process Engineering, 23, 299-319.

Wang, W. C., Sastry, S. K. (2002). Effects of moderate electrothermal treatments on juice yield from cellular tissue. Innovative Food Science and Emerging Technologies. 3 (4), 371-377.

Zareifard, M. R., Ramaswamy, H. S., Trigui, M., Marcotte, M. (2003). Ohmic heating behaviour and electrical conductivity of two-phase food Systems. Innovative Food Science and Emerging Technologies, 4, 45-55.

Zhong, T., Lima, M. (2003). The effect of ohmic heating on vacuum drying rate of sweet potato tissue. Bioresource Technology, 87, 215-220.

Table 1. The parameters and properties used in model calculations

\begin{tabular}{lc}
\hline Property or parameter (unit) & value \\
\hline Density $\left(\mathrm{kg} / \mathrm{m}^{3}\right)$ & 1071.7 \\
Specific heat $(\mathrm{J} / \mathrm{kg} . \mathrm{K})$ & 3850 \\
\hline
\end{tabular}


Table 2. Nonlinear analysis of covariance table for a completely randomized design with a factorial treatment structure for the lemon juice

\begin{tabular}{lccc}
\hline Source & Sum of Squares & $\mathrm{df}$ & $\mathrm{F}$ \\
\hline Corrected Model & $5.81^{\mathrm{a}}$ & 7 & 901.2 \\
Intercept & 7.63 & 1 & 8280 \\
$\mathrm{~T}$ & 1.76 & 1 & 19.4 \\
$\mathrm{~V}$ & 0.054 & 3 & 5153 \\
$\mathrm{~T} \times \mathrm{V}$ & 0.129 & 3 & 46.8 \\
Error & 0.203 & 220 & \\
Total & 100.7 & 228 & \\
Corrected Total & 6.02 & 227 & \\
\hline
\end{tabular}

${ }^{\mathrm{a}} \mathrm{R}^{2}=0.970$ (Adjusted $\mathrm{R}^{2}=0.965$ )

Table 3. The constants and coefficients of liner model of lemon juice during ohmic heating

\begin{tabular}{lccc}
\hline Voltage gradient (V/cm) & $\mathrm{B}$ & $\mathrm{C}$ & $\mathrm{R}^{2}$ \\
\hline 55 & 0.0106 & 0.2298 & 0.987 \\
45 & 0.0058 & 0.2971 & 0.967 \\
35 & 0.01 & 0.2389 & 0.999 \\
30 & 0.0081 & 0.1994 & 0.999 \\
\hline
\end{tabular}

Table 4. Experimental data and the model predictions of lemon juice during ohmic heating

\begin{tabular}{ccccccccc}
\hline $\mathrm{V} / \mathrm{cm}$ & $\mathrm{Q}_{\mathrm{t}}(\mathrm{J})$ & $\mathrm{E}_{\mathrm{g}}(\mathrm{J})$ & $\mathrm{SPC}$ & $\mathrm{T}_{\mathrm{i}}$ & $\mathrm{T}_{\mathrm{f}}$ & $\mathrm{t}_{\exp }$ & $\mathrm{t}_{\mathrm{adb}}$ & $\mathrm{t}_{\mathrm{T}}$ \\
\hline 30 & 7899 & 8620 & 0.92 & 19.8 & 73 & 44 & 44 & 44 \\
35 & 6834 & 7678 & 0.90 & 19.7 & 73 & 24 & 22 & 30 \\
45 & 5496 & 6521 & 0.84 & 20 & 74 & 18 & 15 & 24 \\
55 & 4518 & 8382 & 0.54 & 20.3 & 74.7 & 11 & 11 & 13 \\
\hline
\end{tabular}




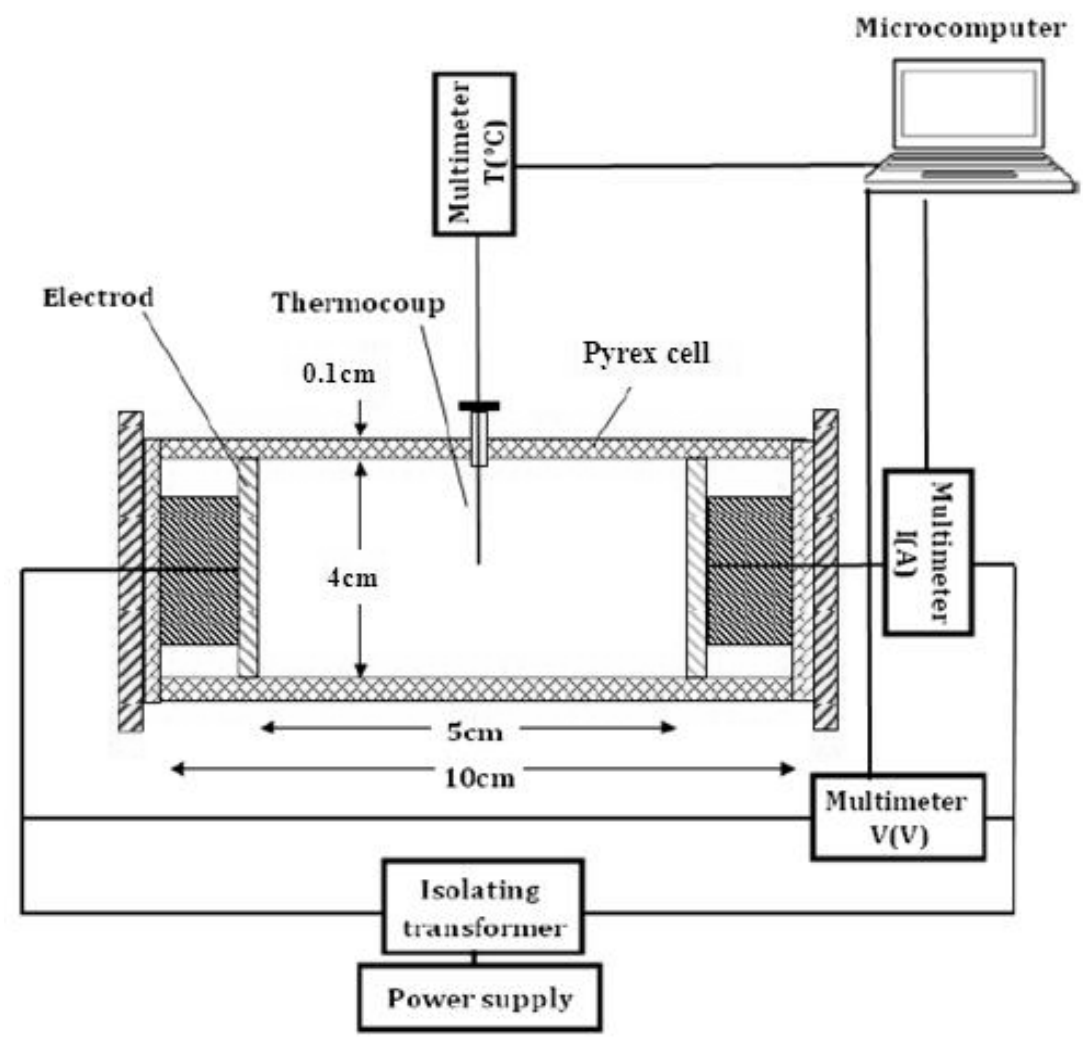

Figure 1. Schematic diagram of the ohmic heating system

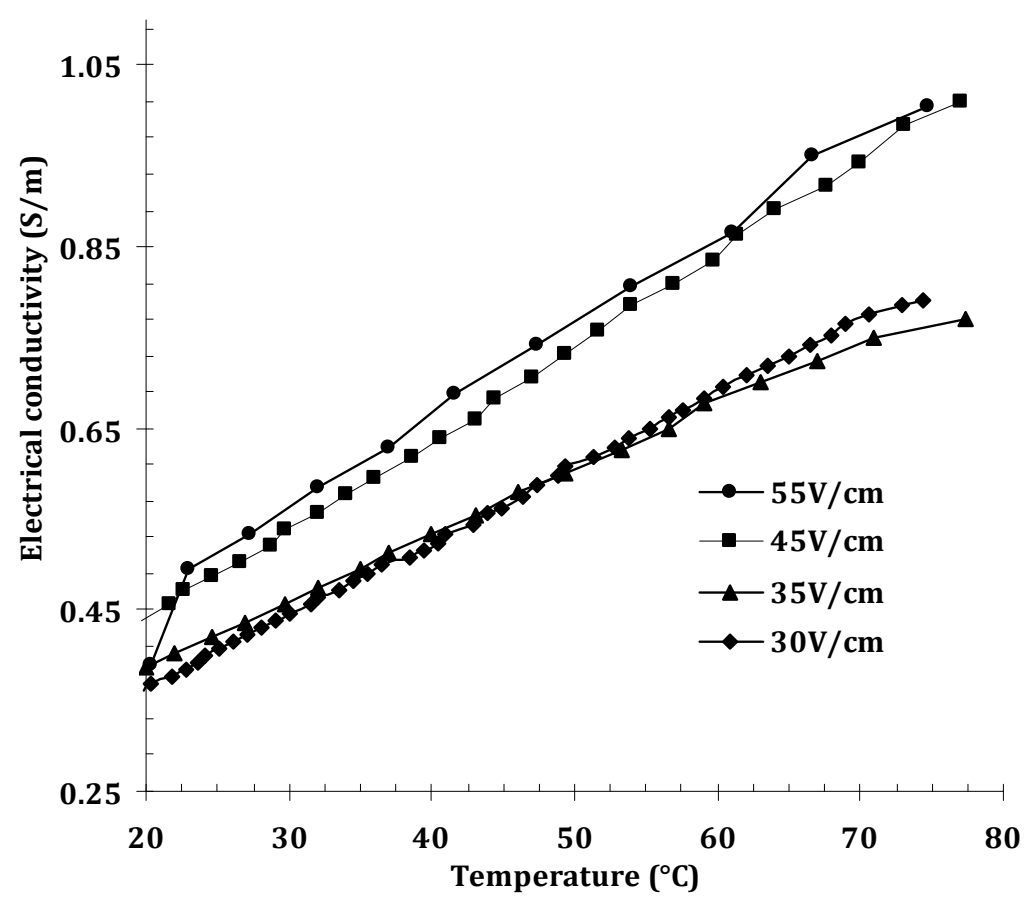

Figure 2. Electrical conductivity changes of lemon juice during ohmic heating at different voltage gradients 


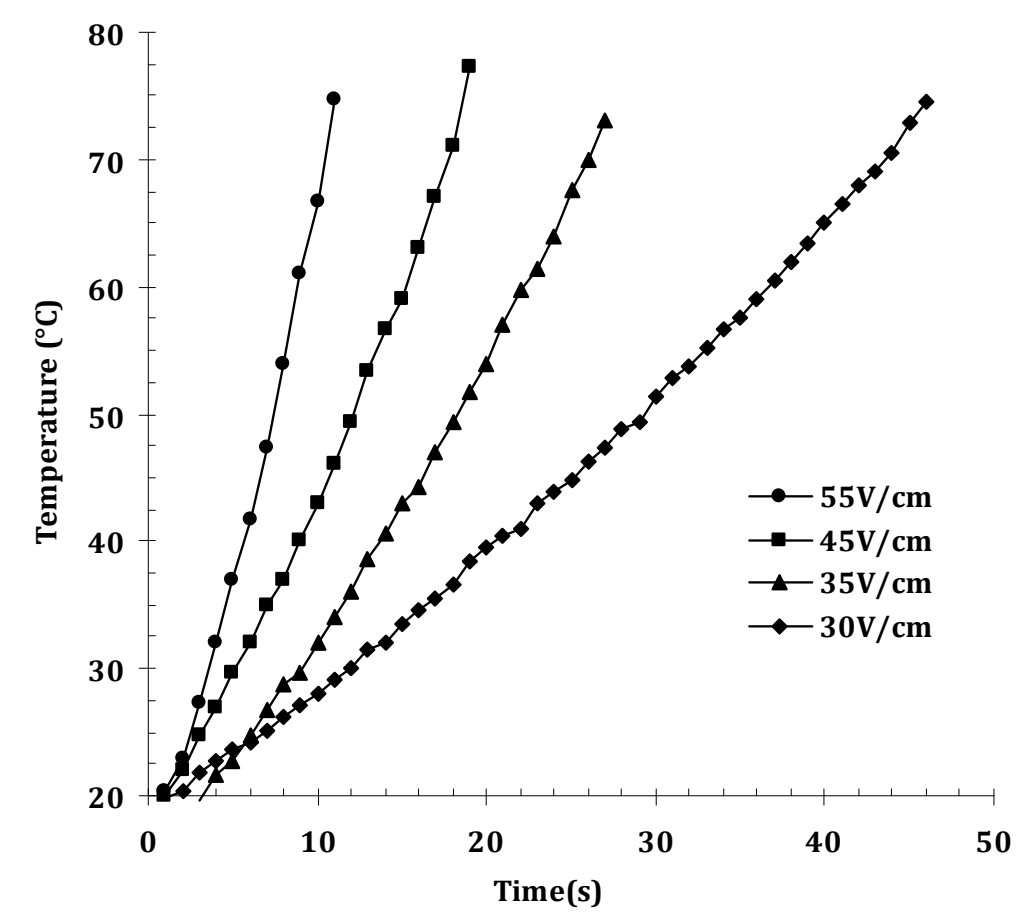

Figure 3. Ohmic heating curves of lemon juices at different voltage gradients 